\title{
Dynamic Negative Bias Temperature Instability and Comprehensive Modeling in PMOS Body-Tied FinFETs
}

Hyunjin Lee, Choong-Ho Lee*, Donggun Park* and Yang-Kyu Choi

Dept. of EECS, Korea Advanced Institute of Science and Technology, Daejeon 305-701, Korea

*Device Research Team, Semiconductor R\&D Division, Samsung Electronics Co., Kyunggi-Do 449-711, Korea

Email:jinlee@eeinfo.kaist.ac.kr, Phone: +82-42-869-5477, Fax: +82-0505-869-3477

This paper presents a novel approach to estimate the rising and falling behavior of $\mathrm{N}^{\text {th }}$-order on-state current by dynamic negative bias temperature instability (DNBTI). For the first time, a modified DNBTI model in PMOS body-tied FinFETs was proposed and compared with experimental data. The approach can provide a quick estimation of periodic DNBTI behavior by stress and recovery. The DNBTI behaviors dependent upon stress bias, fin width, body temperature, and substrate bias were analyzed. The proposed model closely matched with the measured static-lifetime.

\section{Introduction}

Multi-gate FinFET structures have strengths of high robustness on short-channel effects and superior scalability using conventional processes $[1,2]$. However, due to the scalability, NBTI starts to limit the device reliability of digital and analog circuits $[3,4]$. Previous studies indicate the improvement on NBT-stress with a wide fin width $\left(\mathrm{W}_{\mathrm{Fin}}\right)$ in the SOI as well as in the body-tied FinFETs because of the hole concentration reduction at the $\mathrm{Si}_{-} \mathrm{SiO}_{2}$ interface $[5,6]$. Recently, recovery of the NBTI has become a concern for the AC-lifetime prediction $[7,8]$.

\section{Experiments}

Detailed fabrication processes of body-tied FinFETs have already been reported [2]. For the dynamic BT-stress, negative biases $\left(\mathrm{V}_{\mathrm{G}}=\mathrm{V}_{\mathrm{TO}}-\mathrm{V}_{\text {Stress }}\right)$ for stress-states and positive biases $\left(\mathrm{V}_{\mathrm{G}}=\mathrm{V}_{\mathrm{TO}}+\mathrm{V}_{\text {Stress }}\right)$ for recovery-states were applied to the gate of body-tied FinFETs for $100 \mathrm{sec}$. Additionally, the source, drain and substrate were grounded with various Temp: $50^{\circ} \mathrm{C}, 80^{\circ} \mathrm{C}, 125^{\circ} \mathrm{C}$, and $150^{\circ} \mathrm{C}$. A $\mathrm{V}_{\text {sub }}$ of $-0.2 \mathrm{~V}$ was applied to ensure the virtualfloating body effects, even in the body-tied FinFETs, which can mimic SOI FinFETs [4]. To investigate the fin width dependence of DNBTI behaviors, $W_{\text {Fin }}$ of $30 \mathrm{~nm}, 50 \mathrm{~nm}$, and $100 \mathrm{~nm}$ were used with a gate length of $100 \mathrm{~nm}$ and a gate oxide thickness of $1.7 \mathrm{~nm}$. The DNBTI monitoring scheme was reported in ref. [5].

\section{Results and Discussions}

The on-current $\left(\mathrm{I}_{\mathrm{ON}}\right)$ degradation and enhancement of the PMOS body-tied FinFETs are shown in Fig. 1 with various DC stress biases $\left(\mathrm{V}_{\mathrm{Stress}}\right)$. $\mathrm{I}_{\mathrm{ON}}$ degradation represents an increment of $\mathrm{N}_{\mathrm{it}}$ and $\mathrm{N}_{\mathrm{ot}}$ by $\mathrm{Si}-\mathrm{H}$ bond breaking; furthermore, its enhancement represents $\mathrm{N}_{\mathrm{ot}}$ neutralization and $\mathrm{N}_{\mathrm{it}}$ re-passivation. [7,9]. To achieve an analytical and comprehensive understanding of DNBTI with $\mathrm{V}_{\text {Stress}}, \mathrm{Temp}, \mathrm{W}_{\mathrm{Fin}}$, and floating body effects, a previous model [10] was revamped with fitting parameter, $\kappa$.

Fig. 2 shows $\mathrm{I}_{\mathrm{ON}}$ variation on stress- and recovery-states. After the $1^{\text {st }}$ stress, $n$ was $0.25 ; n$ was then reduced to \pm 0.05 after the $1^{\text {st }}$ recovery and the $2^{\text {nd }}$ stress. The coefficient $n=0.25$ comes from the diffusion mechanism, which is the same value of planar bulk-devices [10], and the reduction of $n(=0.05)$ comes from the lock-in mechanism [7]. Fig. 3 shows that the exponent, n, was independent from $\mathrm{W}_{\text {Fin }}(30 \mathrm{~nm} \sim 100 \mathrm{~nm}), \mathrm{V}_{\text {Stress }}(2.4 \mathrm{~V} \sim 3.4 \mathrm{~V})$, Temp $\left.50^{\circ} \mathrm{C}, 125^{\circ} \mathrm{C}\right)$, and $V_{\text {sub }}(0 \mathrm{~V},-0.2 \mathrm{~V})$. Fig. 4 and Fig. 5 show the $Y_{1^{-}}$ intercept of the $1^{\text {st }}$ stress using Eq. 2 and the $\mathrm{I}_{\mathrm{ON}}$ degradation versus $-1 / \mathrm{k}_{\mathrm{B}} \mathrm{T}$ to extract $E_{a}$ using Eq. 4 . The coefficient $m$ is affected by $\mathrm{V}_{\text {sub }}$ but not by $\mathrm{W}_{\mathrm{Fin}}$, when the $E_{a}$ decreases with the increment of $\mathrm{W}_{\mathrm{Fin}}$ and $\mathrm{V}_{\text {sub. }}$ Fig. 6 shows the exponents for the $\mathrm{E}_{\mathrm{ox}}$, such as $m_{1}$ $\left(\mathrm{V}_{\text {sub }}=0 \mathrm{~V}\right.$, FinFET $) ; m_{2}\left(\mathrm{~V}_{\text {sub }}=-0.2 \mathrm{~V}\right.$, FinFET); and $m_{3}$ (single-gate bulk-FET), and the activation energy of the body-tied FinFETs and the single-gate bulk-FETs, which correspond to an infinite fin width. $m$ did not show $\mathrm{W}_{\text {Fin }}$ dependency, but they were dependent on $\mathrm{V}_{\text {sub }}$. Comparing $m_{3}$ and $m_{1,2}$, an increase was seen as the number of gates increased, i.e., $m_{l, 2}>m_{3}[10,11] . E_{a}$ was larger in the single-gate bulk planar MOSFETs than in the body-tied FinFETs $[8,10-13] . E_{a}$ decreased as the $\mathrm{W}_{\mathrm{Fin}}$ decreased and a negative $\mathrm{V}_{\text {sub }}$ was applied. Table 1 summarizes the extracted coefficients, $A, n, m$, and $E_{a}$ after the $1^{\text {st }}$ stress. The virtual floating body formed by applying $\mathrm{V}_{\text {sub }}=-0.2 \mathrm{~V}$ resulted in the decrement of $m$ and $E_{a}$. Decrement of $E_{a}$ caused more degradation of the device performance. Fig. 7 shows the $\Delta \mathrm{I}_{\mathrm{ON}}$ at $\mathrm{V}_{\text {sub }}=0 \mathrm{~V}$ and $-0.2 \mathrm{~V}$. The cross point of $\Delta \mathrm{I}_{\mathrm{ON}}$ between $A\left(E_{o x}\right)^{m}$ and $\exp \left(-E_{a} / k_{B} T\right)$ represents that $E_{a}$ is dominant at a low $\mathrm{E}_{\mathrm{ox}}$ field and that $m$ is dominant at a high $E_{o x}$ field. The virtual floating device shows worse device performance in the low $\mathrm{E}_{\mathrm{ox}}$ region, i.e., in the $E_{a}$ dominant region. However, the virtual floating device shows better device performance in the high $\mathrm{E}_{\mathrm{ox}}$ region, i.e., in the $m$ dominant region. Since an actual operative region of the device is at a low $E_{o x}$, the NBTI is worse at a SOI than at a bulk substrate, which is consistent with a previous report [5].

Fig. 8 shows an estimation of the $\mathrm{I}_{\mathrm{ON}}$ variation using the measured data under the DNBT-stress. Guidelines of $\Delta \mathrm{I}_{\mathrm{ON}} / \mathrm{I}_{\mathrm{ON}, 0}$ under the NBT-stress are increased according to $t^{n}$, the power time law. One guideline after the $1^{\text {st }}$ stress was extracted from $t_{\mathrm{s} 1}$ and $\mathrm{t}_{\mathrm{s} 2}$, and it was proportional to the exponent, $n=0.25$. Similarly, the other guideline was extracted from $t_{\mathrm{s} 2}$ and $t_{\mathrm{s} 3}$, and it was proportional to the exponent, $n=0.05$. At the $\mathrm{N}^{\text {th }}$-order, $\Delta \mathrm{I}_{\mathrm{ON}} / \mathrm{I}_{\mathrm{ON}, 0}$ follows the guideline of the $2^{\text {nd }}$ stress [14]. Periodic $\Delta \mathrm{I}_{\mathrm{ON}} / \mathrm{I}_{\mathrm{ON}, 0}$ behavior after the $\mathrm{N}^{\text {th }}$-order stress and recovery is well matched with the proposed DNBTI modified model (Eq. 1) by using parameters in Table 1, the $1^{\text {st }}$ stress measurement data, the $1^{\text {st }}$ and the $2^{\text {nd }}$ guidelines from the $1^{\text {st }}$ and $2^{\text {nd }}$ stress measurement data, and the fitting parameter, $\kappa$. The solid lines of Fig. 9(a)(b) represent the DNBTI profiles modeled using the proposed method. Even using the $1^{\text {st }}$ and $2^{\text {nd }}$ stress-state measurement data, the modeled $\mathrm{N}^{\text {th }}$-order stress and recovery profiles are well matched with the measurement results. The stress bias effects show a different value of $\kappa$ due to the different $E_{o x}$ dominant region. Fig. 10 shows the static-lifetime predicted by the modified DNBTI model at $\mathrm{W}_{\mathrm{Fin}}=50 \mathrm{~nm} \& 100 \mathrm{~nm}$ and $\mathrm{V}_{\text {sub }}=0 \mathrm{~V} \&-0.2 \mathrm{~V}$ with different $\mathrm{V}_{\text {Stress. }}$. The device staticlifetime is defined at $10 \%$ of the drain saturation current. The rootmean square error of measured lifetime $\left(\tau_{\mathrm{me}}\right)$ and modeled lifetime $\left(\tau_{\text {mo }}\right)$ was approximately $16 \%$ (Eq. 5).

\section{Conclusions}

A modified DNBTI model and extraction method were developed to predict the $\mathrm{N}^{\text {th }}$-order DNBTI profile with various $\mathrm{V}_{\text {Stress }}$, Temp, $\mathrm{W}_{\text {Fin }}$, and $\mathrm{V}_{\text {sub }}$. The stress time exponent, $n$, was 0.25 at the $1^{\text {st }}$ stress-state and was changed to \pm 0.05 after the $1^{\text {st }}$ recovery-state. A decrement of $E_{a}$ with a narrower $\mathrm{W}_{\text {Fin }}$ represented the increment in $\mathrm{N}_{\mathrm{it}}$ and device degradation. A virtual floating body indicated a decrement of the coefficients $m$ and $E_{a}$. The modeled static-lifetime coincided well with the measured static-lifetime, showing a root-mean square error of $16 \%$.

\section{References}

[1] Y.-K. Choi et al., IEDM, p.421, 2001. [2] T. Park et al., VLSI, p.135, 2003. [3] V. Reddy et al., IRPS, p.248, 2002. [4] C. Schliinder et al., IRPS, p.5, 2003. [5] H. Lee et al., EDL, Vol.26, p.326, 2005. [6] H. Kufluoglu et al., IEDM, p.113, 2004. [7] S. Rangan et al., IEDM, p.341, 2003. [8] V. Huard et al., IRPS, p.40, 2004. [9] S. Tsujikawa et al., VLSI, p.139, 2003. [10] S. Ogawa et al., Phys. Review B, Vol.51, p.4218, 1995. [11] M. Houssa et al., IEDM, p.121, 2004. [12] G. Haller et al., J. Appl. Phys., Vol.56, p.1844, 1984. [13] N. Kimizuka et al., VLSI, p.92, 2000. [14] Y. Mitani et al., IEDM, p.117, 2004. 
$\Delta I_{O N}=A \kappa t^{n}\left(E_{o x}\right)^{m} \exp \left(-E_{a} / k_{B} T\right) \cdots \cdots \cdots \cdots \cdot E q .1$ $\log \left(\Delta I_{O N}\right)=n \log (t)+Y_{1} \quad \cdots \cdots \cdots \cdots \cdots \cdots \cdots \cdots \cdots \cdots \cdots \cdots \cdots \cdots \cdot 2$

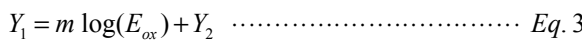
$\log \left(\Delta I_{O N}\right)=E_{a}\left(-1 / k_{B} T\right)+Y_{3} \cdots \cdots \cdots \cdots \cdots \cdots \cdots \cdots \cdots \cdots \cdots$

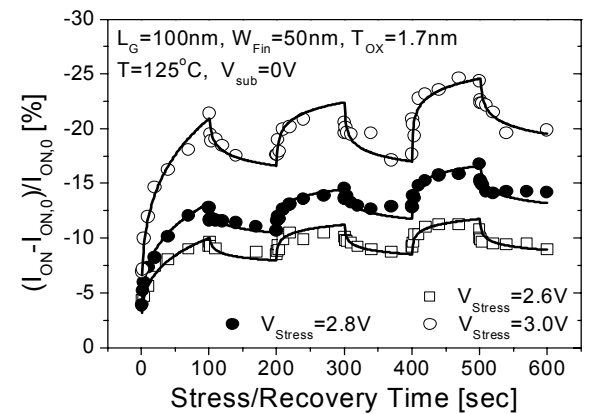

Fig. 1. $\mathrm{I}_{\mathrm{ON}}$ degradation and enhancement versus stress/recovery time for different dynamic NBT-stress and PBT-stress biases.

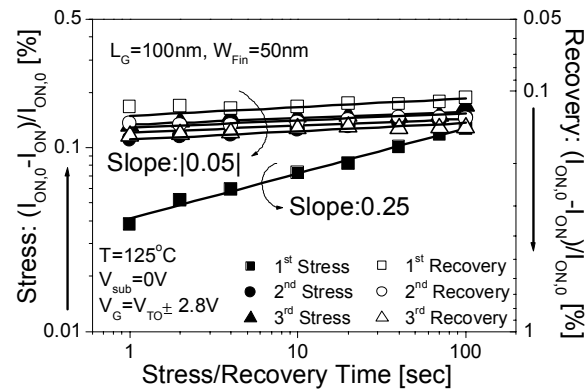

Fig. 2. $\mathrm{I}_{\mathrm{ON}}$ degradation and enhancement with a number of stress- and recovery-states. After the $1^{\text {st }}$ stress, $n$ is fixed to 0.25 and reduced to \pm 0.05 after the $1^{\text {st }}$ recovery and the $2^{\text {nd }}$ stress.

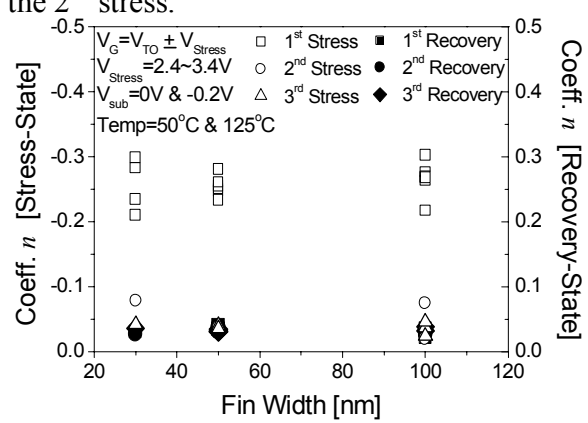

Fig. 3. The coefficient $n$ vs. $\mathrm{W}_{\text {Fin }}$ with various stress and recovery states. The $1^{\text {st }}$ stress $n$ is fixed to the range of $0.2 \sim 0.3$, and the $n$ of the other states are fixed to the range of $\mid 0 \sim 0.1$.

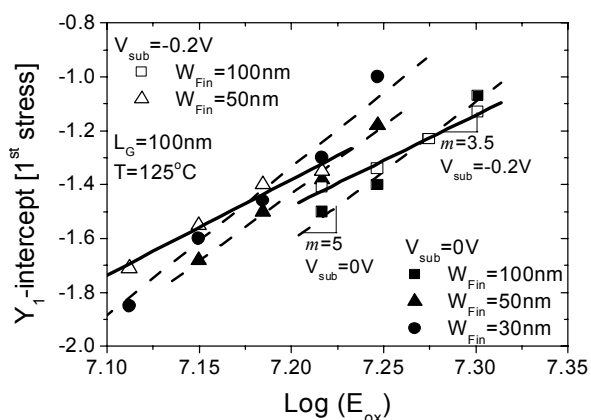

Fig. 4. $\mathrm{Y}_{1}$-intercept of the $1^{\text {st }}$ stress from Eq. 3 versus $E_{o x}$ with various $W_{\text {Fin }}$ and $V_{\text {sub }}$. The coefficient $m$ shows no $\mathrm{W}_{\text {Fin }}$ dependency, but does show $\mathrm{V}_{\text {sub }}$ dependency.

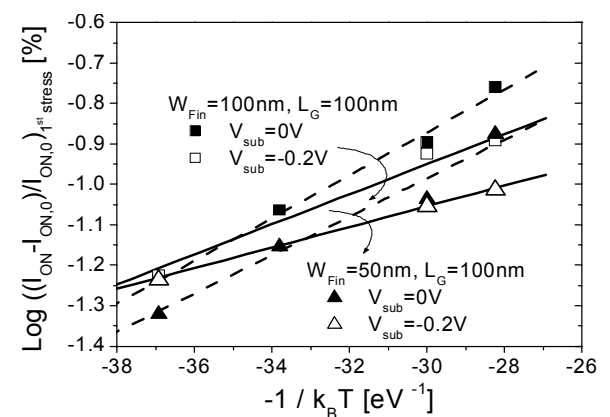

Fig. 5. $\mathrm{I}_{\mathrm{ON}}$ degradation versus $-1 / k_{B} T$ to find the coefficient $E_{a}$, the activation energy. $E_{a}$ decreases with the increment of fin width and as the substrate bias is applied.

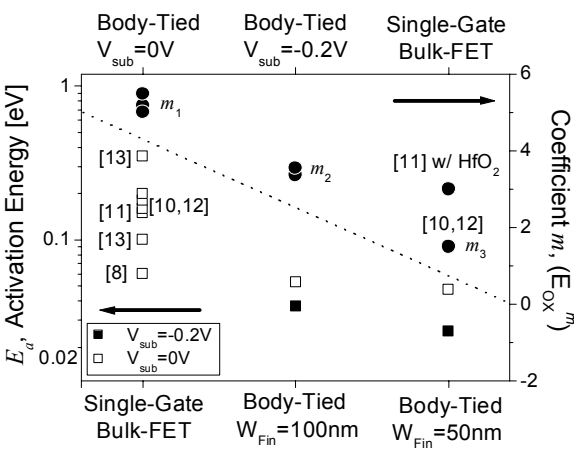

Fig. 6. Right and top axis shows $m$ with a single-gate and body-tied FinFETs $\left(\mathrm{V}_{\text {sub }}=0 \mathrm{~V}\right.$ and $-0.2 \mathrm{~V}$ ). Left and bottom axis shows $E_{a}$ of the body-tied FinFETs with a $\mathrm{W}_{\mathrm{Fin}}$ of 50 $\mathrm{nm}$ and $100 \mathrm{~nm}$, and a single-gate bulk-FET (infinite $\mathrm{W}_{\text {Fin }}$ ).

\begin{tabular}{|c|c|c|c|c|c|}
\hline $\mathrm{W}_{\text {Fin }}$ & $\mathrm{V}_{\text {sub }}$ & $A$ & $n$ & $m$ & $E_{a}$ \\
\hline \multirow{3}{*}{$100 \mathrm{~nm}$} & $0 \mathrm{~V}$ & $2 \times 10^{-37}$ & $\begin{array}{c}0.25 \\
\pm 0.05\end{array}$ & 5 & $0.053 \mathrm{eV}$ \\
\cline { 2 - 6 } & $-0.2 \mathrm{~V}$ & $1 \times 10^{-26}$ & $\begin{array}{c}0.25 \\
\pm 0.05\end{array}$ & 3.5 & $0.037 \mathrm{eV}$ \\
\hline \multirow{3}{*}{$50 \mathrm{~nm}$} & $0 \mathrm{~V}$ & $2 \times 10^{-37}$ & $\begin{array}{c}0.25 \\
\pm 0.05\end{array}$ & 5 & $0.048 \mathrm{eV}$ \\
\cline { 2 - 6 } & $-0.2 \mathrm{~V}$ & $\mathbf{1 \times 1 0 ^ { - 2 6 }}$ & $\begin{array}{c}0.25 \\
\pm 0.05\end{array}$ & 3.5 & $0.025 \mathrm{eV}$ \\
\hline $\begin{array}{c}\text { Bulk } \\
\text { FET }\end{array}$ & - & - & 0.25 & 1.5 & $\begin{array}{c}0.06 \mathrm{eV} \\
0.35 \mathrm{eV}\end{array}$ \\
\hline
\end{tabular}

Table 1. Extracted coefficients $A, n, m$, and $E_{a}$ after the $1^{\text {st }}$ stress with $\mathrm{W}_{\mathrm{Fin}}=50 \mathrm{~nm}, 100$ $\mathrm{nm}$ and $\mathrm{V}_{\mathrm{sub}}=0 \mathrm{~V},-0.2 \mathrm{~V} . E_{a}$ shows $\mathrm{W}_{\mathrm{Fin}}$ dependency, and $A, m$, and $E_{a}$ show $\mathrm{V}_{\text {sub }}$ dependence.

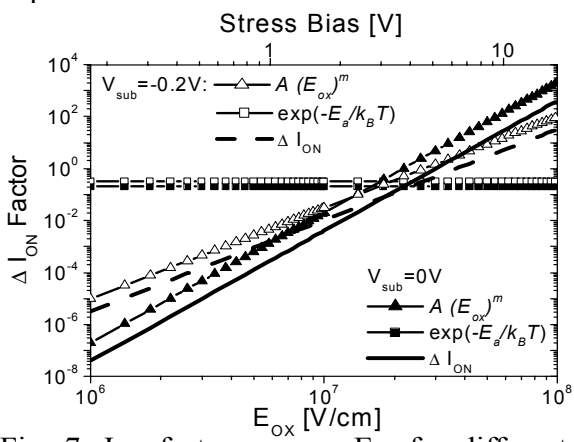

Fig. 7. $\mathrm{I}_{\mathrm{ON}}$ factors versus $\mathrm{E}_{\mathrm{ox}}$ for different substrate biases. The $\mathrm{E}_{\mathrm{ox}}$ dependency of the floating body effect is the correlated results of the factor $A\left(E_{o x}\right)^{m}$ and $\exp \left(-E_{a} / k_{B} T\right)$. The NBTI of the SOI FinFETs was worse than that of the body-tied FinFETs in the low $\mathrm{E}_{\mathrm{ox}}$ region [5].

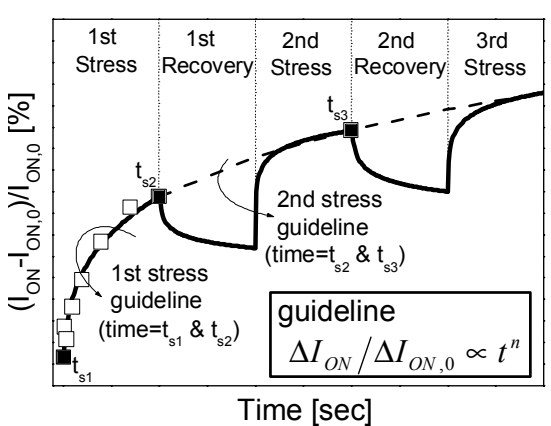

Fig. 8. Periodic $\Delta \mathrm{I}_{\mathrm{ON}} / \mathrm{I}_{\mathrm{ON}, 0}$ under DNBTstress. The $1^{\text {st }}$ stress guideline increased according to $t^{n}$ with $n=0.25$, and changed to $n=0.05$ after the $2^{\text {nd }}$ stress.
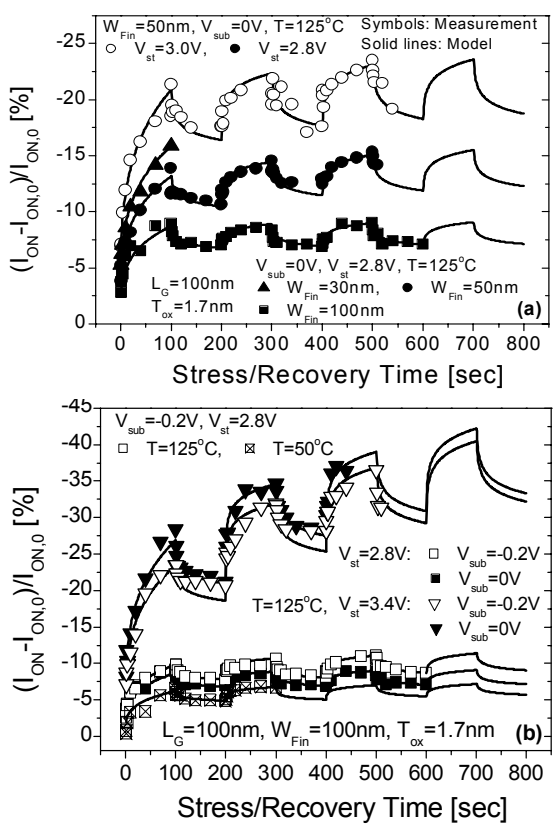

Fig. 9. $\mathrm{I}_{\mathrm{ON}} / \mathrm{I}_{\mathrm{ON}, 0}$ of DNBTI versus stress/recovery time with various (a) $\mathrm{V}_{\text {Stress }}$, $\mathrm{W}_{\text {Fin, }}$ (b) Temperature and $\mathrm{V}_{\text {sub. Solid lines }}$ represent the DNBTI profiles modeled using the proposed method.

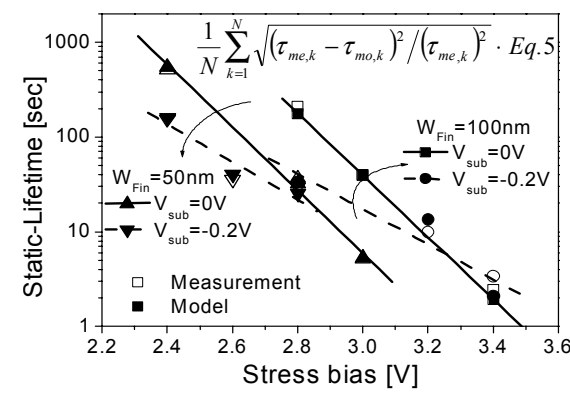

Fig. 10. Measured and modeled staticlifetime at $\mathrm{W}_{\text {Fin }}=50 \mathrm{~nm}, 100 \mathrm{~nm}$ and $\mathrm{V}_{\text {sub }}=0$ $\mathrm{V},-0.2 \mathrm{~V}$ versus $\mathrm{V}_{\text {Stress }}$ according to Eq. 1 and the parameters in Table 1 . The rootmean square error is $16 \%$.

\section{Acknowledgment}

This work was supported in part by Samsung Electronics Co., Ltd., and in part by the National Research Program for the 0.1-Terabit Nonvolatile Memory Development, sponsored by the Korea Ministry of Science and Technology. 